\title{
Electronic Health Records Implementation Readiness: An Integrative Review
}

\author{
Mohammad Alsadi ${ }^{1}$, Ali Saleh ${ }^{2}$ \\ ${ }^{1}$ Abdali Medical Center, Amman, Jordan \\ ${ }^{2}$ School of Nursing, The University of Jordan, Amman, Jordan \\ Email:Mhm4ever@yahoo.com
}

How to cite this paper: Alsadi, M. and Saleh, A. (2019) Electronic Health Records Implementation Readiness: An Integrative Review. Open Journal of Nursing, 9, 152-162. https://doi.org/10.4236/ojn.2019.92014

Received: January 19, 2019

Accepted: February 18, 2019

Published: February 21, 2019

Copyright (c) 2019 by author(s) and Scientific Research Publishing Inc. This work is licensed under the Creative Commons Attribution International License (CC BY 4.0).

http://creativecommons.org/licenses/by/4.0/

\section{(c) (†) Open Access}

\begin{abstract}
Purpose: The purpose of this review was to discuss the status of evidence related to the assessment of readiness of healthcare facilities for e-health initiatives implementation, specifically the common Electronic Health Record (EHR) systems. Methods: An integrative review approach was utilized. The databases of Google Scholar, Scopus, Science Direct, PubMed, Medline, CINAHL, Ovid, ProQuest, and EBSCO host were searched for related evidence published between 2000 and 2018. Results: Seventeen studies were included in the current review. In terms of methodological approach, the included studies were 7 correlational studies, 5 review papers, 4 qualitative papers, and one mixed methods study. At the current integrative review, the themes of complex healthcare change, and the main theme of e-health readiness assessment were identified. Conclusion: Assessing and reporting the levels of readiness for EHRs implementation are highly recommended as it has a high impact on the critically-needed adoption and usage of the implemented system. Selecting the right tool for the right audience to address readiness is essential in the assessment process which is recommended to be conducted early at the road map of the project implementation. Future research is recommended to address readiness for e-health initiatives at the different settings and different target populations including communities where the healthcare facilities functions and service receivers' readiness.
\end{abstract}

\section{Keywords}

Readiness, Assessment, EHR, EMR, E-Health, Implementation

\section{Introduction}

With the rapid development of technology, healthcare industry stakeholders are continuously looking into its utilization to aid in optimizing healthcare short- 
comings [1]. This challenge is concurrent with the steadily increasing demand on healthcare services which is related to the global growth of populations, longer life expectancies, and increased complexity of health conditions, and coupled with an increased attention to provide better quality of healthcare [2]. The implementation of Electronic Health Record (EHR) systems came into the front as a one of the commonly used solutions to promote healthcare delivery and overcome challenges and the core of any e-health systems [3]. International Organization for Standardization (ISO) defined EHRs as "a repository of patient data in digital form, stored and exchanged securely, and accessible by multiple authorized users. It contains retrospective, concurrent, and prospective information and its primary purpose is to support continuous, efficient and quality integrated health" [4].

Implementing EHRs system set the promise that it will help in providing better evidence-based healthcare [2], higher levels of completeness, accuracy, validity, access and coordinated communication of patient information, safer prescribing, and utility of electronic health records for clinical diagnoses [5] [6], better clinical decision support [7] [8], and increased medical practice efficiency [9].

On the other hand, EHRs implementation represents a disruptive change in the healthcare workplace. It affects healthcare providers, service receivers, administrators, organizational culture, policies and systems of healthcare delivery [2] [3]. In order to harvest the promised benefits of EHRs system implementation, it is important to address organizational and staff readiness for EHRs systems implementation and usage [10]. Readiness assessment, as a part of pre-implementation preparations, becomes an essential requirement prior to the actual implementation of EHRs [11]. Being not ready for EHRs implementation at the healthcare settings may lead to many obstacles during the implementation process. It may also lead to low adoption of healthcare professionals to use the EHRs system. The ultimate result can be the EHRs implementation failure which may have negative impacts on patient care due to the loss of important clinical and administrative data [10]. This paper attempts to summarize the efforts of scholars in studying the healthcare organizations readiness for introducing e-health solutions.

\section{Materials and Methods}

The databases of Google Scholar, Scopus, Science Direct, PubMed, Medline, CINAHL, Ovid, ProQuest, and EBSCO host were searched for related evidence published between 2000 and 2018. The search was conducted using different combinations of keywords and abbreviations relevant to the current study including "electronic health records, electronic medical records, EHR, EMR, e-health, information systems, implementation, assessment, and readiness". The search was done initially using the combination of the keywords "Electronic Health Records readiness assessment". Then, separate search attempts were 
conducted where the rest of the keywords were added incrementally to the basic keywords separated by commas until all keywords were included in the federated search bar. The inclusion criteria for articles considered in this review were 1) published in English language, 2) published between the year 2000 and 2018, 3) related to readiness for e-health solutions at healthcare facilities, and 4) no restrictions were applied on the article type. Incomplete reports in the form of conference proceedings, abstracts, or posters, editorial papers, or opinion papers were excluded from this review.

As shown in Figure 1, the initial search results executed at the different search engines came back with 1456 articles the list of articles titles were exported from the federated search results into MS excel sheet and compiled together in one comprehensive list. Then, upon removing the duplicates from the list, 654 article titles left. Then, the primary researcher went through the 654 titles and excluded 540 articles as the titles were not relevant to focus of this integrative review; 114 articles left. The sifting procedure continued with reading the abstracts of 114 articles by the primary researcher, 90 articles were then excluded and 24 were included. 24 articles were printed in full text and reviewed carefully. Upon reviewing the full text, 7 articles were excluded as it does not relate to main focus of this review as set in the inclusion criteria and the purpose of this review. 17 articles were included at the current review. Based on the included studies methodologies, the 17 articles included were 7 correlational studies, 5 review papers, 4 qualitative papers, and one mixed methods study.

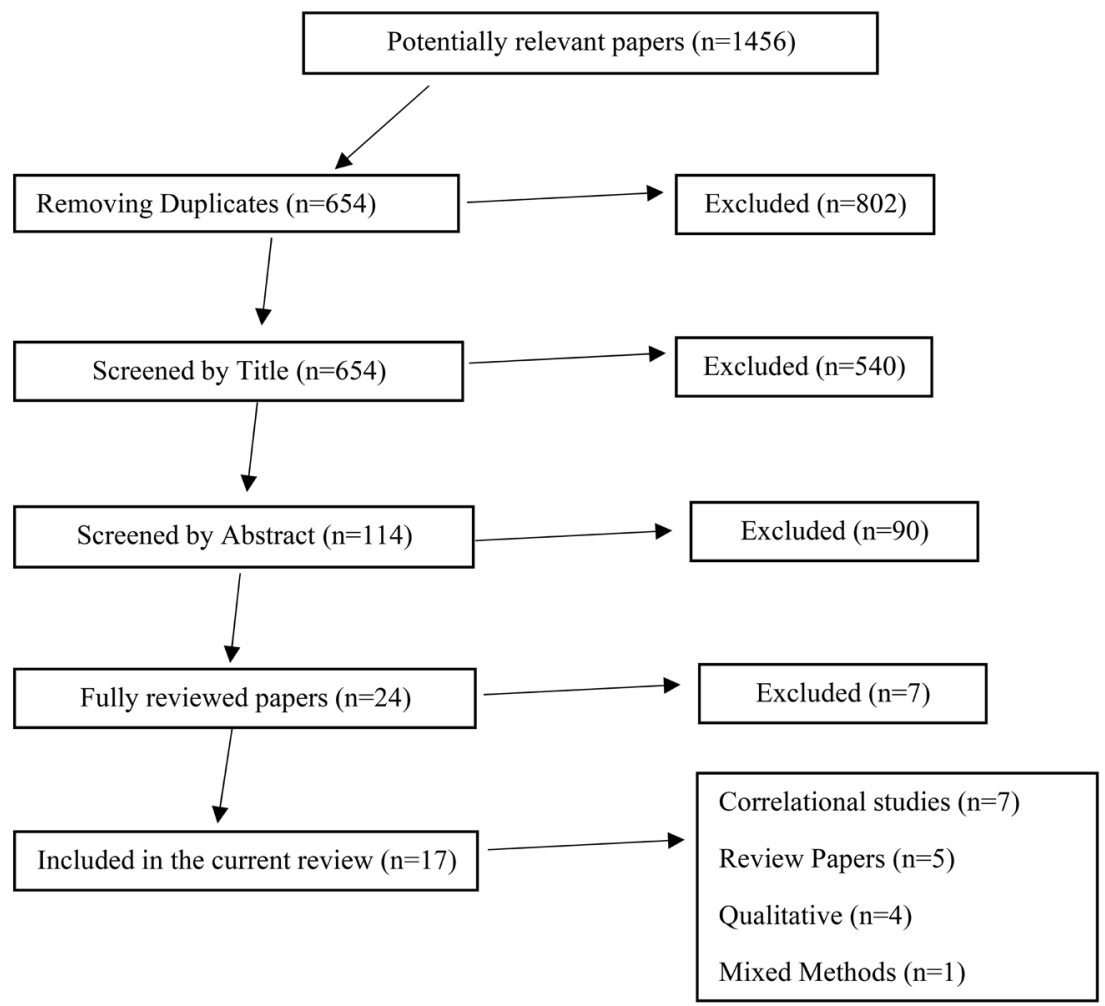

Figure 1. Literature review flow chart. 


\section{Results}

Seventeen articles were reviewed and included. As shown in Table 1, for each included article, the data of authors, year of publication, purpose of the study, sample size, design, and main findings were extracted and presented. Authors of this review examined the studies to identify the themes discussed. All of the included studies identified readiness for e-health as an essential step before implementing such a change in any given healthcare facility.

Table 1. Summary of studies included in the review.

\begin{tabular}{|c|c|c|c|c|c|}
\hline$\#$ & Authors (Year) & Purpose & Sample Size & Design & Main Findings \\
\hline 1 & $\begin{array}{l}\text { Holt, Armenakis, Field, } \\
\text { and Harris (2007) [13] }\end{array}$ & $\begin{array}{l}\text { To develop an instrument } \\
\text { to measure the individual } \\
\text { level of readiness for } \\
\text { organizational change }\end{array}$ & 900 & Correlational & $\begin{array}{l}\text { The development of } 26 \text {-item organizational } \\
\text { readiness scale that measure its four main } \\
\text { constructs: change-specific efficacy, } \\
\text { appropriateness, management support, and } \\
\text { personal valence. }\end{array}$ \\
\hline 2 & $\begin{array}{l}\text { Kgasi and Kalema } \\
(2014)[2]\end{array}$ & $\begin{array}{l}\text { To investigate the } \\
\text { determinants of e-health } \\
\text { readiness in rural areas of } \\
\text { South Africa }\end{array}$ & 61 & Correlational & $\begin{array}{l}\text { The need for change was identified as the } \\
\text { most influential determinant of e-health } \\
\text { readiness, while societal readiness was the } \\
\text { least important. }\end{array}$ \\
\hline 3 & Weiner (2009) [14] & $\begin{array}{l}\text { To define organizational } \\
\text { readiness for change } \\
\text { conceptually setting its } \\
\text { determinants and } \\
\text { outcomes }\end{array}$ & Not applicable & Qualitative & $\begin{array}{l}\text { Readiness for change was defined conceptually } \\
\text { and consisted of two main constructs: change } \\
\text { commitment, and change efficacy. } \\
\text { Three key determinants of change } \\
\text { implementation were identified: task demands, } \\
\text { resource availability, and the situational } \\
\text { factors. }\end{array}$ \\
\hline 4 & $\begin{array}{l}\text { Durrani, Khoja, Naseem, } \\
\text { Scott, Gul, and Jan (2012) } \\
{[16]}\end{array}$ & $\begin{array}{l}\text { To assess the need and } \\
\text { readiness for e-health at } \\
\text { healthcare facilities in } \\
\text { Pakistan }\end{array}$ & 10 & $\begin{array}{l}\text { Mixed Qualitative } \\
\text { Methods: } \\
\text { Interviews and } \\
\text { Focus groups }\end{array}$ & $\begin{array}{l}\text { The needs of healthcare institutions in terms } \\
\text { of e-health ware categorized into the groups: } \\
\text { provision of care needs (lack of human } \\
\text { resources, restricting government policies, } \\
\text { difficulties in referral systems, issues with } \\
\text { service utilization); learning needs (i.e. lack of } \\
\text { continuous education, and lack of information } \\
\text { and research); and information management } \\
\text { needs (issues with paper-based records, and } \\
\text { communication of information). }\end{array}$ \\
\hline 5 & $\begin{array}{l}\text { Najaftorkaman, } \\
\text { Ghapanchi, Talaei-Khoei, } \\
\text { and Ray (2013) [17] }\end{array}$ & $\begin{array}{l}\text { To categorize the areas } \\
\text { of research related to the } \\
\text { field of Electronic } \\
\text { Medical Records (EMR) }\end{array}$ & $\begin{array}{l}155 \\
\text { papers } \\
\text { published } \\
\text { between } 2011 \\
\text { and } 2012\end{array}$ & $\begin{array}{l}\text { Literature } \\
\text { Review }\end{array}$ & $\begin{array}{l}\text { Eight areas of EMR related research were } \\
\text { identified: design and implementation, } \\
\text { evaluation, adoption, impacts, medical } \\
\text { research, integration, EMR data design and } \\
\text { management, and policy and standards. } \\
\text { EMR is used to improve the quality of } \\
\text { healthcare and enhances efficiency, on the } \\
\text { other side, healthcare providers and health } \\
\text { service managers reported negative } \\
\text { perceptions. }\end{array}$ \\
\hline 6 & $\begin{array}{l}\text { Biruk, Yilma, Andualem, } \\
\text { and Tilahun (2014) [18] }\end{array}$ & $\begin{array}{l}\text { To assess health } \\
\text { professionals' readiness } \\
\text { and to acceptance and } \\
\text { usage of electronic } \\
\text { medical records in Ethiopia }\end{array}$ & 606 & Correlational & $\begin{array}{l}\text { The majority of the study participants ( } 71.3 \%) \\
\text { did have good knowledge and attitudes toward } \\
\text { EMR systems. Factors that are associated with } \\
\text { EMR readiness are: gender, attitudes toward } \\
\text { EMR, knowledge about EMR, and computer } \\
\text { literacy. }\end{array}$ \\
\hline
\end{tabular}




\section{Continued}

Li, Land, Chattopadhyay, Land, and Ray (2008) [3]

Jennett, Gagnon, and Brandstadt (2005) [20]

Wickramasinghe, Fadlalla,

Khoja, Scott, Casebeer,

10 Mohsin, Ishaq, and Gilani (2007) [22]

Al-Rawajfah and Tubaishat

To explore the views of

nurses in Jordan

(2017) [24]

Ghazisaeidi, Ahmadi,

12 Sadoughi, and Safdari (2014) [11]

a result of integrating

published frameworks

To review published

studies that addresses

readiness for e-health

to assess readiness for

e-health at the national level

To present and discuss

developing countries

facilitators for e-health

implementation

To develop e-health

readiness assessment

model for public and

educational hospitals in
To presents the development of E-Health

Readiness Assessment

Framework (EHRAF) as 6 main papers Qualitative

components of previously

4 Main

papers/

frameworks

Literature

Review

To develops a framework

Not applicable

published tools to measure Two main

readiness for e-health in papers

regarding the barriers and 2793

30

Iran

E-health readiness has four main constructs: core readiness (i.e. realization of problems, and providers satisfaction), engagement readiness (i.e. potential negative impacts, willingness to accept training, and recognition of benefits), technological readiness (i.e. Hardware, software, network, IT support, providers past IT experiences), and societal readiness (i.e. internal communications among healthcare providers, communication links with other institutions).

Four readiness models resulted from the search process. They varied across settings, such as rural outpatient practices, hospice programs, rural communities, as well as government agencies, national associations, and organizations. Common themes across models included: an appreciation of practice context, strong leadership, and a perceived need to improve practice.

The e-health readiness framework consists of four main pre-requisites (technology architecture, standardization policies and protocols, user accessibility, and governmental policies), four main impacts (IT education, economic standing, morbidity, and culture), and the implications of these pre-requisites and impacts to the goals of e-health.

Two main tools were presented: one targeting healthcare managers and the second one targeting healthcare providers.

Literature Review

Correlational Both tools were developed using participatory action research, reviewing existing tools and reviewing literature examine determinants of e-health readiness.

The facilitating factors for e-health in Jordan as perceived by nurses were: incentives to buy e-health systems, the availability of technical support, and additional incentives to use the e-health systems.

The barriers were: the cost of buying e-health solutions, lack of information technology staff, and disruption to clinical workflows.

E-health readiness assessment model was developed that consists of five dimensions: cultural, leadership and management, technical infrastructure, governance, and operational. 


\begin{tabular}{|c|c|c|c|c|c|}
\hline 13 & Stadelmann (2012) [12] & $\begin{array}{l}\text { To assess e-health } \\
\text { readiness at university } \\
\text { hospitals in Egypt }\end{array}$ & 6 interviews & Qualitative & $\begin{array}{l}\text { Implementing e-health solutions will lead to } \\
\text { the improvement of the following areas: } \\
\text { Human resources management, governance, } \\
\text { and finance. } \\
\text { E-health readiness areas to be targeted are: } \\
\text { culture, leadership, strategy, information } \\
\text { management, clinical and administrative staff, } \\
\text { training, workflows, accountability, finance, } \\
\text { patient involvement, IT infrastructure and IT } \\
\text { management. }\end{array}$ \\
\hline 14 & Cherry (2011) [23] & $\begin{array}{l}\text { To evaluate the } \\
\text { psychometric properties } \\
\text { of E-health readiness } \\
\text { assessment tools at long } \\
\text { Term Care (LTC) facilities } \\
\text { in the unites States }\end{array}$ & 93 & Correlational & $\begin{array}{l}\text { The LTC Readiness Assessment Tool for EHR } \\
\text { Implementation is supported to be used for } \\
\text { readiness assessment. Internal reliability was } \\
\text { supported with a Cronbach's alpha coefficient } \\
\text { of } 0.95 \text {. }\end{array}$ \\
\hline 15 & $\begin{array}{l}\text { Yusif, Hafeez-Baig, and } \\
\text { Soar (2017) [19] }\end{array}$ & $\begin{array}{l}\text { To examine e-health } \\
\text { readiness assessment tools } \\
\text { and formulate } \\
\text { recommendations }\end{array}$ & 63 & $\begin{array}{l}\text { Systematic } \\
\text { Review }\end{array}$ & $\begin{array}{l}\text { Six e-readiness themes were identified: } \\
\text { Technological readiness, } \\
\text { Core/Need/Motivational readiness, acceptance } \\
\text { and usage readiness, organizational readiness, } \\
\text { IT skills/training/learning readiness, } \\
\text { engagement Readiness, and societal readiness. }\end{array}$ \\
\hline 16 & $\begin{array}{l}\text { Ajami, Ketabi, Isfahani, } \\
\text { and Heidari (2011) [15] }\end{array}$ & $\begin{array}{l}\text { To present the e-health } \\
\text { readiness assessment in } \\
\text { the roadmap of e-health } \\
\text { solutions implementation } \\
\text { and discuss the main areas } \\
\text { in readiness assessment }\end{array}$ & 45 & $\begin{array}{l}\text { Literature } \\
\text { Review }\end{array}$ & $\begin{array}{l}\text { E-health implementation road map consists } \\
\text { of } 6 \text { stages: assessment, planning, selection, } \\
\text { implementation, evaluation, and improvement. } \\
\text { The first stage of readiness assessment is } \\
\text { critical for successful e-health solution. The } \\
\text { readiness assessment should target } \\
\text { infrastructure readiness, technical architecture } \\
\text { readiness, and process readiness. }\end{array}$ \\
\hline 17 & $\begin{array}{l}\text { Saleh, Khodor, } \\
\text { Alameddine, and Baroud } \\
(2016)[10]\end{array}$ & $\begin{array}{l}\text { To assess the e-health } \\
\text { readiness at primary health } \\
\text { centers in Lebanon }\end{array}$ & 213 & Correlational & $\begin{array}{l}\text { Majority of care providers at primary centers } \\
\text { in Lebanon are ready for implementation of } \\
\text { e-health solutions. } \\
\text { Factors that affect e-health readiness are: } \\
\text { personal beneficence, management } \\
\text { support, change efficacy, and level of comfort } \\
\text { using computers }\end{array}$ \\
\hline
\end{tabular}

Healthcare industry has its complexity in the move toward e-health solutions, mainly the implementation of EHR systems to replace the traditional paper-based records. It is imperative that healthcare stakeholders should address the readiness for this change. While, EHRs vendors tend to present the different promised benefits for such systems and direct the attention of "customers" toward the urgent need for its implementation, readiness is overlooked throughout the whole process. Stadelmann concluded that implementing e-health solutions will lead to the improvement of human resources management, governance, and finance. E-health readiness areas to be targeted are: culture, leadership, strategy, information management, clinical and administrative staff, training, workflows, accountability, finance, patient involvement, IT infrastructure and IT manage- 
ment [12]. In the race of EHRs implementation and the huge literature discussing the EHRs, readiness for implementation is just recently addressed in literature. Healthcare industry should be "ready" for this "disruptive" change before they actually move toward it, paying the attention to the argument that traditional change theories, may not be sufficient to address this change in the complex healthcare settings [1] [13] [14]. Ajami, Ketabi, Isfahani, and Heidari presented an e-health implementation road map that consists of 6 stages: assessment, planning, selection, implementation, evaluation, and improvement. The first stage of readiness assessment is critical for successful e-health solution. The readiness assessment should target infrastructure readiness, technical architecture readiness, and process readiness [15].

Studies addressed many factors that may affect the readiness for technology implementation, i.e. EHR system, in healthcare. At the organizational level, factors such as training and education for the implemented technology solution, use of familiar terminologies within the system, involving the end users early during the development and the implementation process, workload considerations, access to computers at the point of care, and the availability of business continuity support after completing the implementation process [16] [17]. At the staff level, perceived ease of use, perceived usefulness, resources availability, the actual usage of the implemented technology, and computer literacy were reported as key factors in being ready to adopt, accept, use and being satisfied in using the implemented technology [18]. Yusif, Hafeez-Baig, and Soar identified six e-readiness themes: technological readiness, core/need/motivational readiness, acceptance and usage readiness, organizational readiness, IT skills/training/learning readiness, engagement readiness, and societal readiness [19].

To assess the readiness for technology implementation, many scholars worked on exploring the readiness construct, where multiple dimensions of the construct were identified and defined aiming to reach the full picture of readiness dynamics, scope, boundaries, and indicators [3]. Efforts started from a broad worldview of change, readiness to change, then focused on readiness for technology innovations including e-health and EHRs systems [3]. Moreover, multiple efforts were put there to develop a comprehensive tool to assess the factors contained at the construct of readiness for technology, quantitatively, qualitatively, and using mixed methods [3]. Some efforts focused on the patients' readiness in addition the staff readiness [20], others went to assess the public readiness for change in introducing technology at the healthcare in addition the staff readiness [20] [21], but the huge effort and weight of attention was directed toward the organizational readiness including the staff readiness as it was considered the core readiness construct that determine the success or the failure of a change initiative [14] [20] [21] [22]. Cherry presented the Long-Term Care (LTC) facilities Readiness Assessment Tool for EHR Implementation [23]. Ghazisaeidi, Ahmadi, Sadoughi, and Safdari developed e-health readiness assessment model was developed that consists of five dimensions: cultural, leadership and 
management, technical infrastructure, governance, and operational [11].

Despite the diversity in exploring readiness, developed tools looked at the staff readiness, as the most important element of an organization, as the core of assessment for readiness and the other targets where the add-on areas to examine [3] [13] [20] [21] [22]. If the staffs are not ready for the technology implementation, the system will not be adopted and it can be abandoned [3]. An example of studies that addressed staff is the one conducted by Al-Rawajfah and Tubaishat. In sample of 2793 nurses form 26 hospitals; they explored the barriers and facilitators of EHRs system usage. The results showed that the positive reinforcement in the form of reimbursement, the availability of effective technical assistance and the incentives to buy the EHRs systems were the facilitators to use the EHRs system among nurses, while the financial burden of getting an EHRs system, deficiency in information technology staff, and the disruption the clinical workflows were the barriers to use the EHRs system by nurses [24]. Saleh, Khodor, Alameddine, and Baroud concluded that majority of care providers at primary centers in Lebanon are ready for implementation of e-health solutions. Factors that affect e-health readiness are: personal beneficence, management support, change efficacy, and level of comfort using computers [10].

\section{Discussion}

At the current integrative review, the themes of complex healthcare change, and the main theme of e-health readiness assessment were identified.

It is important to explore the level of readiness among healthcare workers early in the roadmap of e-health implementation [10]. Consequently, and based on the readiness assessment results, healthcare stakeholders should intervene to ensure smooth transition to the new era of e-health usage at the healthcare facilities. The interventions should address the perceptions of healthcare workers toward e-health solutions in terms of its "appropriateness" to be implemented, and the presence of a solid, long lasting "management support". Such administrative interventions may start from developing policies and procedures that supports and facilitates the introduction of e-health solutions [13].

Despite that most of studies recommends to assess the readiness before the intended change, some other studies still measured the readiness after the change and revealed interesting findings. In a study conducted by Coopasami, Knight, and Pete where they assessed the readiness of undergraduate nursing students for the change of education method from the traditional classroom education to e-learning through online classes. They assessed the readiness for the introduction of technology pre and post an intervention that includes a trial of the introduced technology. Guided by the adopted framework, Weiner (2009), they measured three dimensions of readiness: psychological, technological and equipment readiness. Psychological readiness refers to the state of mind for being ready to the introduced change of e-learning, while technological readiness measures whether the students have the appropriate technical skills to pursue 
e-learning, and equipment readiness addresses the availability and appropriateness of the equipment needed for e-learning. Regardless of the resulted level of readiness of nursing students, the reported results showed an increase in the psychological and technological readiness and a decrease in the equipment readiness at the post intervention assessment. The results show that after actually using the technology, perceptions of being ready to in introduction of technology may change to be "more realistic" [25].

Provided the complexity of healthcare delivery system, and the disruptive change of introducing e-health initiatives like the EHRs, a comprehensive and thorough e-health readiness assessment shall be conducted. It is imperative that readiness assessment should be addressed per the different healthcare providers with different strategies and interventions for each segment. Adopting the right tool for the right target audience to asses readiness will greatly impact the direction and acceptance of e-health initiative implementation.

\section{Conclusions}

Assessing and reporting the levels of readiness for EHRs implementation and its impact on the critically needed adoption and usage of the implemented system. Academicians and continuous education departments at the healthcare facilities are invited to develop educational programs that may lead to the presence of more ready healthcare workers to adopt the EHRs systems focusing on maximizing its benefits realization and overcoming any implementation and usage challenges. Educational programs, whether during the academic preparation, in-service, or at the continuous education efforts, may enhance healthcare workers' perception of "change efficacy" which is the perception of being able to handle the daily work using the EHRs system in skillful and competent manner [13].

Success of the implementation of e-health solutions is a mandatory quest to avoid the waste of the resources invested [26]. In implementing e-health initiatives, i.e. EHRs systems to replace the traditional paper-based documentation, a big change is inflicted on healthcare providers, patients, organizations, and the whole healthcare delivery system. Change occurs not simply due to the introduction of a technology, but because it also includes the design of interconnected health. It imposes the need to re-engineer the routine workflows to effectively and efficiently accommodate the new implemented technology [2]. Therefore, all healthcare workers need to be ready for the change of using advanced technology on their daily work [27]. Otherwise, the promised benefits of EHRs technology may not be harvested, and system will not be adopted, then; many problems can be inflected including system failure and negative patient care outcomes [10].

This study may envision future research in the fields of health informatics with the focus of EHRs introduction to healthcare. Investigating the readiness for EHRs implementation may guide other researchers to include different populations and settings. Exploring the readiness of patients, communities, different 
healthcare disciplines workers, and administrators at the different healthcare sectors may reveal different factors and areas to work on to optimize the understanding of the total picture in terms of readiness for EHRs system implementation, better perception of its benefits and then enhanced adoption.

\section{Conflicts of Interest}

The authors declare no conflicts of interest regarding the publication of this paper.

\section{References}

[1] Kgasi, M. and Kalema, B. (2014) Assessment E-Health Readiness for Rural South African Areas. Journal of Industrial and Intelligent Information, 2, 131-135. https://doi.org/10.12720/jiii.2.2.131-135

[2] Bowles, K.H. (2014) Developing Evidence-Based Tools from EHR Data. Nursing management, 45, 18-20. https://doi.org/10.1097/01.NUMA.0000444881.93063.7c

[3] Li, J., Land, L.P.W., Chattopadhyay, S. and Ray, P. (2008) E-Health Readiness Framework from Electronic Health Records Perspective. GlobDev 2008, 4.

[4] ISO, T. 20514 (2005) Health Informatics-Electronic Health Record Definition, Scope and Context Standard. International Organization for Standardization (ISO), Geneva.

[5] Goetz, D.G., Kuzel, A.J., Feng, L.B., DeShazo, J.P. and Love, L.E. (2012) EHRs in Primary Care Practices: Benefits, Challenges, and Successful Strategies. The American Journal of Managed Care, 18, e48-e54.

[6] Sek, A.C., Cheung, N.T., Choy, K.M., Wong, W.N., Tong, A.Y., Fung, V.H., Fung, M. and Ho, E. (2007) A Territory-Wide Electronic Health Record-From Concept to Practicality: The Hong Kong Experience. Studies in Health Technology and Informatics, 129, 293-296.

[7] Stewart, W.F., Shah, N.R., Selna, M.J., Paulus, R.A. and Walker, J.M. (2007) Bridging the Inferential Gap: The Electronic Health Record and Clinical Evidence. Health Affairs, 26, w181-w191. https://doi.org/10.1377/hlthaff.26.2.w181

[8] Zusman, E.E. and Vinokur, Y. (2012) Clinical Decision Support Systems: Key to Making EHR an Improvement. Neurosurgery, 71, N12-N14.

https://doi.org/10.1227/01.neu.0000419707.79663.e7

[9] Silow-Carroll, S., Edwards, J.N. and Rodin, D. (2012) Using Electronic Health Records to Improve Quality and Efficiency: The Experiences of Leading Hospitals. Vol. 17, The Commonwealth Fund, 1-40.

[10] Saleh, S., Khodor, R., Alameddine, M. and Baroud, M. (2016) Readiness of Healthcare Providers for eHealth: The Case from Primary Healthcare Centers in Lebanon. BMC Health Services Research, 16, 644. https://doi.org/10.1186/s12913-016-1896-2

[11] Ghazisaeidi, M., Ahmadi, M., Sadoughi, F. and Safdari, R. (2014) An Assessment of Readiness for Pre-Implementation of Electronic Health Record in Iran: A Practical Approach to Implementation in General and Teaching Hospitals. Acta Medica Iranica, 52, 532-544.

[12] Stadelmann, J. (2012) Assessing Readiness for E-Health in Egypt: A Case Study of Cairo University Hospitals. Ph.D. Dissertation, School of Global Affairs and Public Policy, The American University in Cairo, Cairo.

[13] Holt, D.T., Armenakis, A.A., Feild, H.S. and Harris, S.G. (2007) Readiness for Or- 
ganizational Change: The Systematic Development of a Scale. The Journal of Applied Behavioral Science, 43, 232-255. https://doi.org/10.1177/0021886306295295

[14] Weiner, B.J. (2009) A Theory of Organizational Readiness for Change. Implementation Science, 4, 67. https://doi.org/10.1186/1748-5908-4-67

[15] Ajami, S., Ketabi, S., Isfahani, S.S. and Heidari, A. (2011) Readiness Assessment of Electronic Health Records Implementation. Acta Informatica Medica, 19, 224-227. https://doi.org/10.5455/aim.2011.19.224-227

[16] Durrani, H., Khoja, S., Naseem, A., Scott, R.E., Gul, A. and Jan, R. (2012) Health Needs and eHealth Readiness Assessment of Health Care Organizations in Kabul and Bamyan, Afghanistan/Évaluation des besoinsen matière de santé et de la préparation à la cybersanté dans des établissements de soins de santé à Kaboul et Bamyan (Afghanistan). Eastern Mediterranean Health Journal, 18, 663.

https://doi.org/10.26719/2012.18.6.663

[17] Najaftorkaman, M., Ghapanchi, A.H., Talaei-Khoei, A. and Ray, P. (2013) Recent Research Areas and Grand Challenges in Electronic Medical Record: A Literature Survey Approach. The International Technology Management Review, 3, 12-21. https://doi.org/10.2991/itmr.2013.3.1.2

[18] Biruk, S., Yilma, T., Andualem, M. and Tilahun, B. (2014) Health Professionals' Readiness to Implement Electronic Medical Record System at Three Hospitals in Ethiopia: A Cross Sectional Study. BMC Medical Informatics and Decision Making, 14, 115. https://doi.org/10.1186/s12911-014-0115-5

[19] Yusif, S., Hafeez-Baig, A. and Soar, J. (2017) e-Health Readiness Assessment Factors and Measuring Tools: A Systematic Review. International Journal of Medical Informatics, 107, 56-64. https://doi.org/10.1016/j.ijmedinf.2017.08.006

[20] Jennett, P.A., Gagnon, M.P. and Brandstadt, H.K. (2005) Preparing for Success: Readiness Models for Rural Telehealth. Journal of Postgraduate Medicine, 51, 279.

[21] Wickramasinghe, N.S., Fadlalla, A.M., Geisler, E. and Schaffer, J.L. (2005) A Framework for Assessing E-Health Preparedness. International Journal of Electronic Healthcare, 1, 316-334. https://doi.org/10.1504/IJEH.2005.006478

[22] Khoja, S., Scott, R.E., Casebeer, A.L., Mohsin, M., Ishaq, A.F.M. and Gilani, S. (2007) e-Health Readiness Assessment Tools for Healthcare Institutions in Developing Countries. Telemedicine and e-Health, 13, 425-432.

https://doi.org/10.1089/tmj.2006.0064

[23] Cherry, B. (2011) Assessing Organizational Readiness for Electronic Health Record Adoption in Long-Term Care Facilities. Journal of Gerontological Nursing, 37, 14-19. https://doi.org/10.3928/00989134-20110831-06

[24] Al-Rawajfah, O. and Tubaishat, A. (2017) Barriers and Facilitators to Using Electronic Healthcare Records in Jordanian Hospitals from the Nurses' Perspective: A National Survey. Informatics for Health and Social Care, 44, 1-11. https://doi.org/10.1080/17538157.2017.1353998

[25] Coopasami, M., Knight, S. and Pete, M. (2017) e-Learning Readiness amongst Nursing Students at the Durban University of Technology. Health SA Gesondheid (Online), 22, 300-306. https://doi.org/10.4102/hsag.v22i0.1059

[26] Blaya, J.A., Fraser, H.S. and Holt, B. (2010) E-Health Technologies Show Promise in Developing Countries. Health Affairs, 29, 244-251.

https://doi.org/10.1377/hlthaff.2009.0894

[27] Hebda, T. and Calderone, T.L. (2010) What Nurse Educators Need to Know about the TIGER Initiative. Nurse Educator, 35, 56-60.

https://doi.org/10.1097/NNE.0b013e3181ced83d 